\title{
Irmtraud Bender
}

\section{Baumaßnahmen 2007}

Im Sommer wurde begonnen, die Glasfassaden des Gebäudes komplett in mehreren Bauabschnitten zu sanieren. Zuvor waren in 2006 die Jalousien in jenen Bereichen ausgetauscht worden, in denen die alten Fenster verbleiben sollten. Diese sollen im Jahr 2009 in einem letzten Bauabschnitt durch neue ersetzt werden.

Die neuen Fassaden sind in Holz-Aluminium-Profilen gearbeitet und entsprechen mit neuer Glastechnik auch neuen Licht- und Wärmeschutzbestimmungen. Farbe und Maße der neuen Fenster sind unverändert, weil der architektonische Charakter des Bibliotheksgebäudes erhalten bleiben sollte.

Zur Sanierung der ersten Großfensterfläche wurde im Juni der Bereich Information sowohl von innen als auch von außen eingerüstet, die Jalousien demontiert und die Fenster herausgenommen. Da die Gebäudetragkonstruktion von jeher unterdimensioniert gewesen war, wurden die tragenden Elemente mit Stahlprofilen verstärkt, bevor man die neue Fassade anbringen konnte. Danach erfolgte die Montage der neuen Jalousien mit neuen, den aktuellsten geltenden Vorschriften entsprechenden Rauchabzugsklappen und intelligenter Steuerungstechnik, durch die auch eine Optimierung der Klimatisierung bewirkt werden kann.

In gleicher Art wurde auch mit den anderen Fassadenteilen verfahren, unter zunehmend schwierigen Wetterbedingungen. Leider war der Sommer 2007 insgesamt recht kühl, so dass bei wochenlang offenstehenden Gebäudefronten die Innentemperaturen nicht mehr als behaglich bezeichnet werden konnten. Die Leidensfähigkeit von Mitarbeitern und Benutzern wurde auf eine harte Probe gestellt.

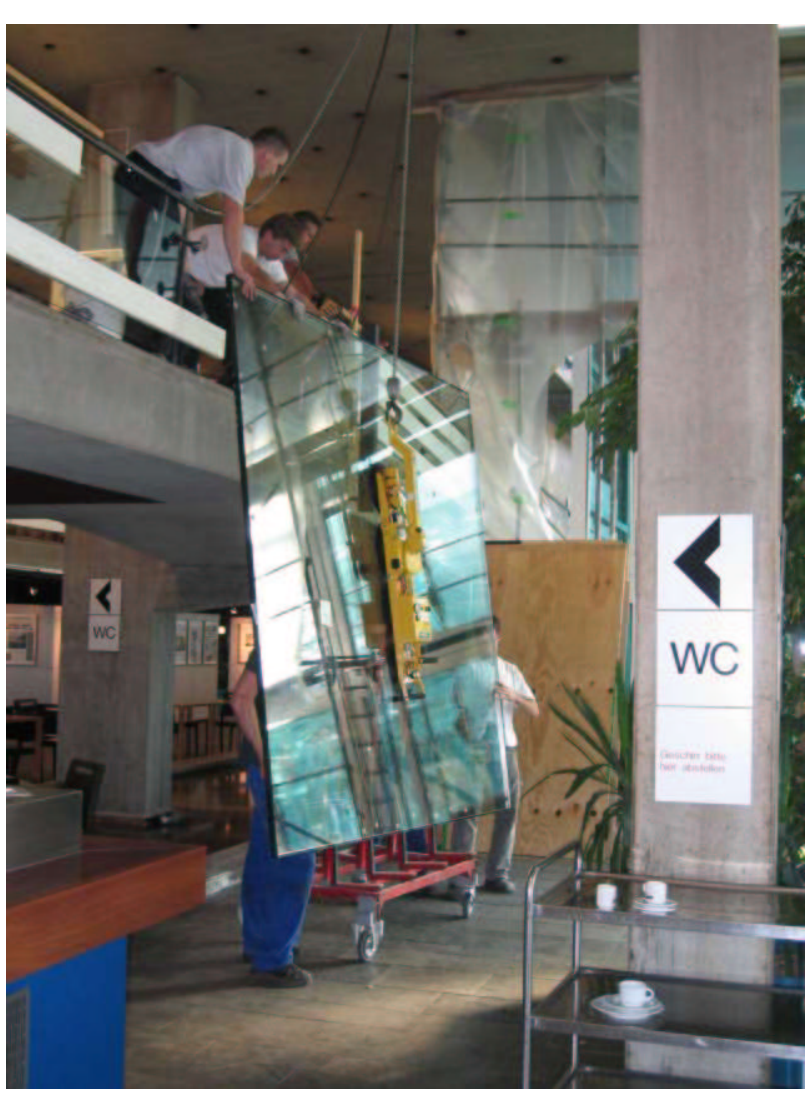


Erst im Herbst kamen die drei Eingänge nacheinander an die Reihe. Zwei davon mussten dabei aus Sicherheitsgründen für die Öffentlichkeit immer zugleich begehbar bleiben.

Die beiden Zugänge auf der Garderobenebene blieben in der Gestaltung unverändert. Ein rollstuhlgerechter Eingang von der Südseite wurde noch zusätzlich eingerichtet.

Der Haupteingang aus Richtung Konrad-Adenauer-Straße wurde ganz neu gestaltet.

Der dunkle, abweisend wirkende Windfang ist nun durch eine Drehtüre ersetzt, die wesentlich mehr Licht in den Bereich der un-

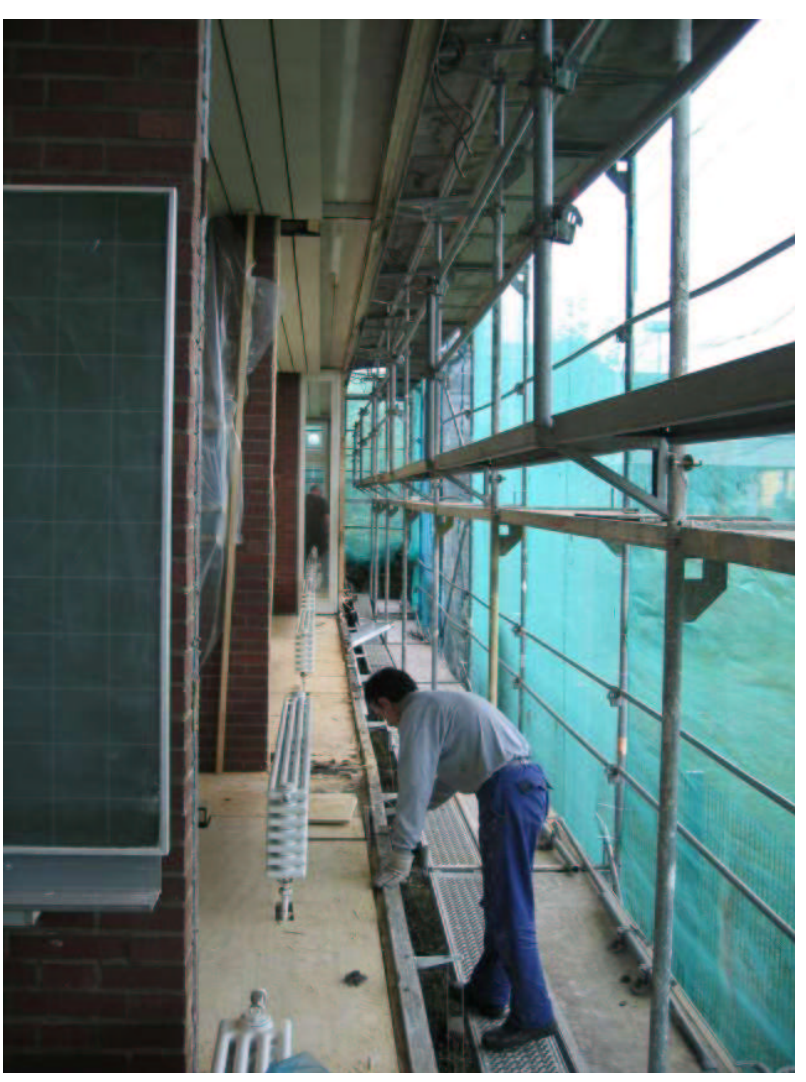
teren Halle bringt. Außerdem waren die Holzbrücke und die Holztreppe davor schon lange nicht mehr verkehrssicher. Helle Granitschweller, die auch für die Gestaltung der Stufen verwendet wurden, geben jetzt dem Eingang ein neues Gesicht.

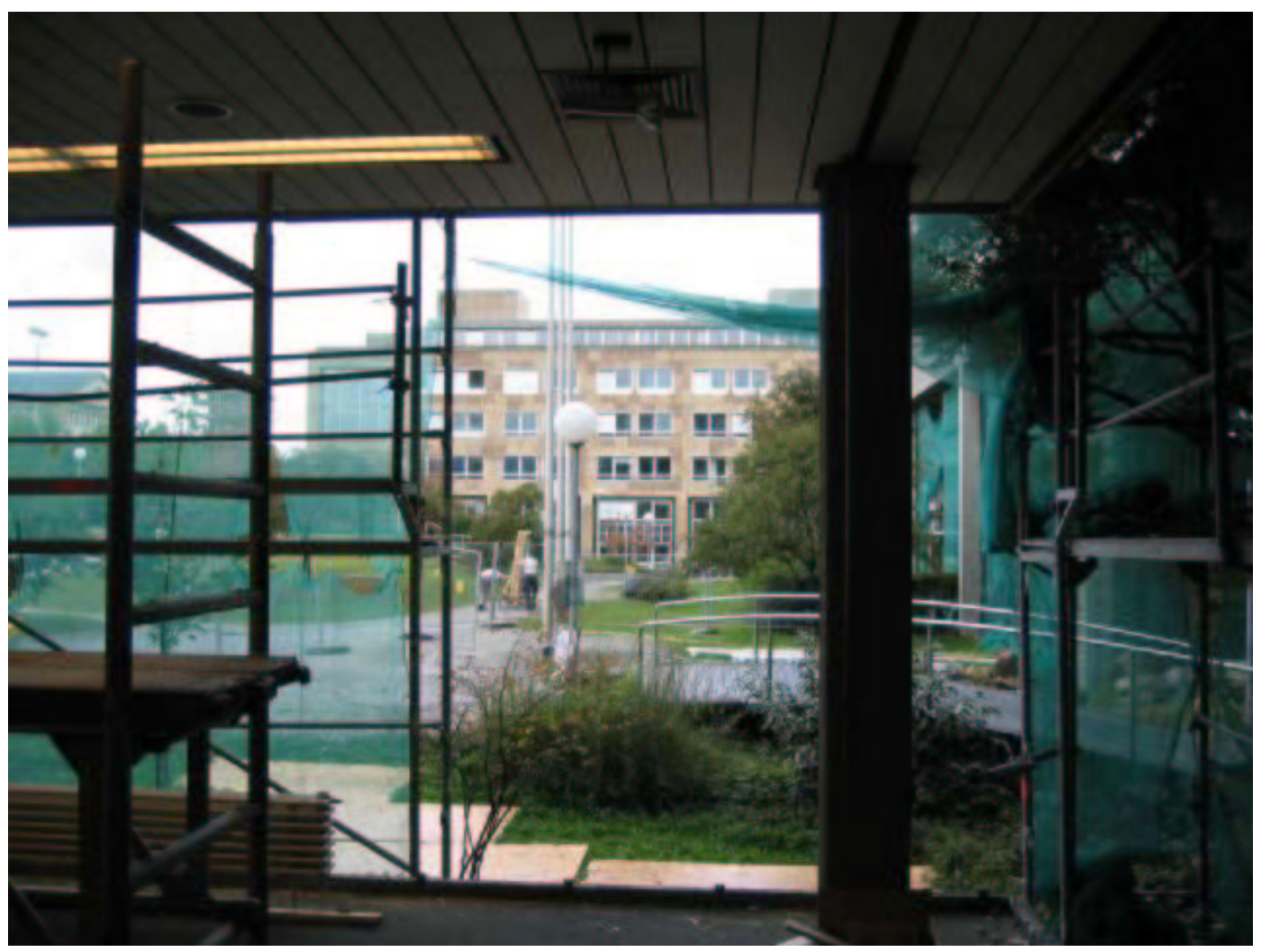


Im Zuge der Fassadensanierung des Gebäudeteils Musiklesesaal, Mitarbeiterraum und Vortragssaal fiel der Entschluss, den Vortragsraum umfassend zu sanieren und dabei die Tontechnik und die Beleuchtung neuen Erfordernissen anzupassen.

Mit außerplanmäßig bewilligten Mitteln wurde der längst überfällige Einbau einer Brandmeldeanlage in der Dependance der Bibliothek, Gaisburgstr. 4a, verwirklicht.

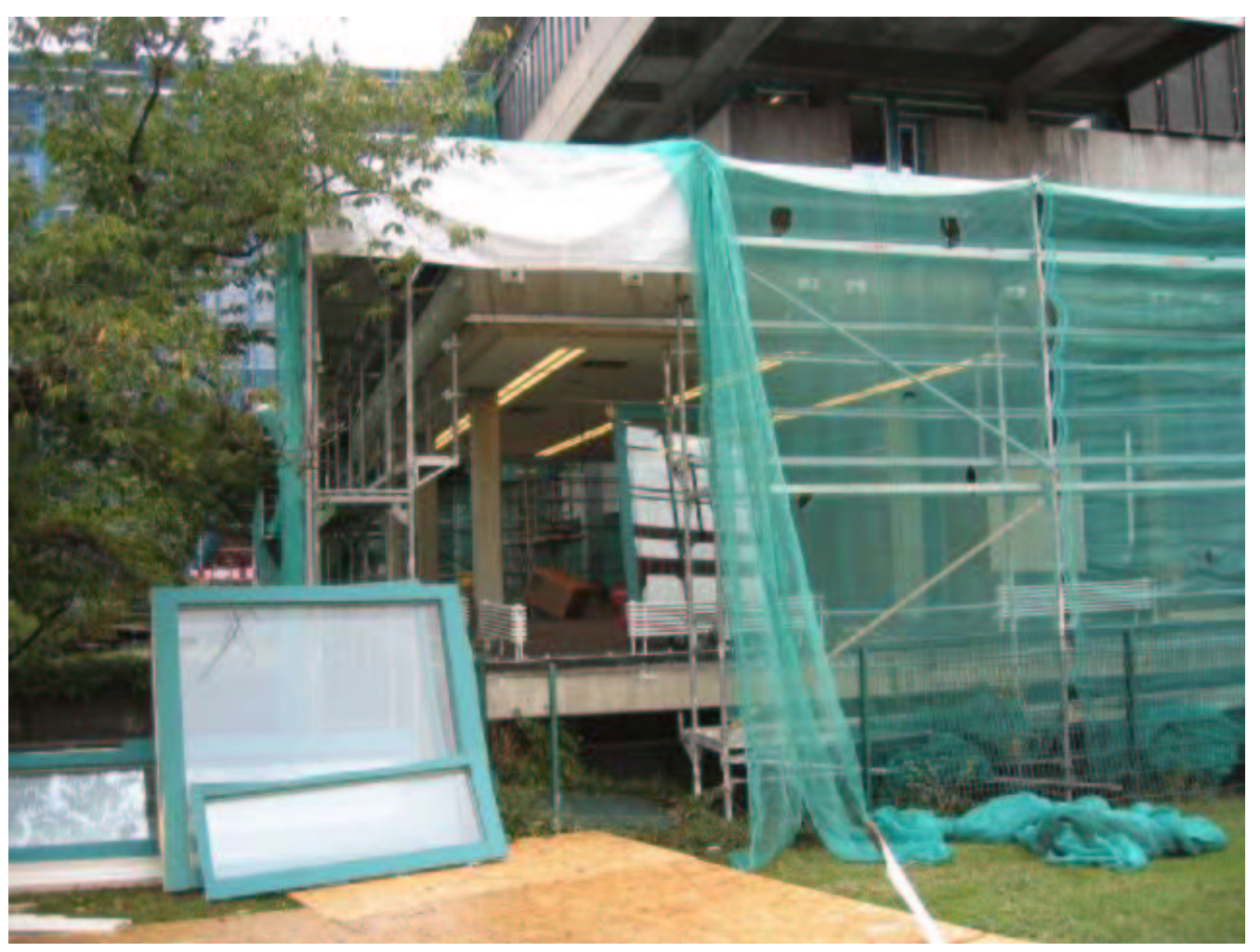

Blick in den Vortragsraum 